\title{
A study about the relevance of adding acetylsalicylic acid in primary prevention in subjects with type 2 diabetes mellitus: effects on some new emerging biomarkers of cardiovascular risk
}

Giuseppe Derosa ${ }^{1,2,3^{*}}$, Amedeo Mugellini $^{1}$, Rosa M Pesce ${ }^{1}$, Angela D'Angelo ${ }^{1,3}$ and Pamela Maffioli ${ }^{1,4}$

\begin{abstract}
Aim: To evaluate the relevance of adding acetylsalicylic acid (ASA) in primary prevention in subjects with type 2 diabetes mellitus.

Methods: 213 patients with type 2 diabetes mellitus and hypertension were randomized to amlodipine 5 mg, or amlodipine $5 \mathrm{mg}+$ ASA $100 \mathrm{mg}$ for 3 months (Phase A); then, if adequate blood pressure control was reached patients terminated the study; otherwise, amlodipine was up-titrated to $10 \mathrm{mg} /$ day for further 3 months and compared to amlodipine $10 \mathrm{mg}+$ ASA $100 \mathrm{mg}$ (Phase B). We assessed at baseline, at the end of Phase A, and at the end of Phase $B$ the levels of some new emerging biomarkers of cardiovascular risk including: high sensitivity $C$-reactive protein (Hs-CRP), adiponectin (ADN), tumor necrosis factor- $\alpha$ (TNF- $\alpha$ ), interleukin-1 $\beta$ (IL-1 $\beta)$, myeloperoxidase (MPO), soluble CD40 ligand (sCDL40).

Results: Compared to baseline, at the end of Phase A, patients treated with amlodipine 5 mg + ASA 100 mg showed a statistically significant reduction of Hs-CRP (-15.0\%), TNF- $\alpha(-21.7 \%)$, MPO (-9.7\%), and sCDL40 (-15.7\%), and a statistically significant increase of ADN (+15.0\%). These values were significantly better than the ones obtained with amlodipine alone. Similarly, at the end of Phase B, amlodipine $10 \mathrm{mg}+\mathrm{ASA}$ significantly lowered Hs-CRP (-18.8\%), TNF- $\alpha(-15.0 \%), M P O(-9.2 \%)$, and sCDL40 (-20.0\%) and increased ADN (+11.8\%), with a better effect compared to amlodipine alone.
\end{abstract}

Conclusion: All biomarkers considered were significantly improved by ASA addition. These data suggest that the use of ASA in primary prevention could be useful in patients with type 2 diabetes mellitus and hypertension.

Trial registration: ClinicalTrials.gov: NCT02064218

Keywords: Acetylsalicylic acid, Amlodipine, Cardiovascular risk, Hypertension, New emerging biomarkers, Primary prevention

\section{Background}

Cardiovascular diseases are the main cause of death, hospitalization and disability among people with type

\footnotetext{
*Correspondence: giuseppe.derosa@unipv.it

${ }^{1}$ Department of Internal Medicine and Therapeutics, University of Pavia, and Fondazione IRCCS Policlinico San Matteo, P.le C. Golgi, 2, 27100 Pavia, Italy

Full list of author information is available at the end of the article
}

2 diabetes mellitus [1]. The incidence of cardiovascular disease in people with diabetes is more than double that in people without diabetes, and the mortality rate after a first myocardial infarction is much higher in people with diabetes $[2,3]$.

For this reason, primary prevention of cardiovascular diseases is very important in people with diabetes. At this regard, the Italian trial MIND-IT (The Multiple 
Intervention in type 2 Diabetes Italy) showed that a multi-factorial intensive intervention in type 2 diabetes is feasible and effective in clinical practice and it is associated with significant and durable improvement in glycated hemoglobin $\left(\mathrm{HbA}_{1 \mathrm{c}}\right)$ and cardiovascular disease risk profile [4]. This was confirmed by the Italian guidelines for the treatment of type 2 diabetes mellitus that recommended primary prevention in patients with diabetes throughout changes in lifestyle, glycemic and lipid control, blood pressure control, and possible introduction of anti-platelet therapy [5]. Also the recently published American Diabetes Association guidelines recommend aspirin therapy (75-162 $\mathrm{mg} /$ day) as a primary prevention strategy in patients at increased cardiovascular risk, including men aged $>50$ years or women aged $>60$ years with, at least, one additional major risk factor (family history of cardiovascular disease, hypertension, smoking, dyslipidemia, or albuminuria) [6]. Despite the higher absolute risk of cardiovascular disease in these patients, however, there is no robust evidence that the use of acetylsalicylic acid (ASA) leads to a favourable benefits-to-risk balance [7]. The JPAD study (Japanese Primary Prevention of Atherosclerosis with aspirin for Diabetes) analyzed the effect of ASA, 81-100 mg, in patients with type 2 diabetes in primary prevention of atherosclerotic events. The risk of cardiovascular disease did not differ between the group receiving ASA and the one that did not, however, among individuals aged 65 years and older, the incidence of atherosclerotic events was significantly lower in the group receiving ASA compared with the group who did not [8]. On the other hand, the POPADAD trial (Prevention of progression of arterial disease and diabetes) trial, conducted in patients with diabetes mellitus and asymptomatic peripheral arterial disease, did not provide evidence to support the use of aspirin in primary prevention of cardiovascular events and mortality in the population with diabetes [9].

Recently some new emerging biomarkers, including soluble CD40 ligand (sCD40L) and serum myeloperoxidase (MPO), have been linked to a higher cardiovascular risk [10]. On this basis the aim of this study was to evaluate the relevance of adding ASA in primary prevention in subjects with type 2 diabetes mellitus. To verify this, we evaluated ASA effects on the levels of some new emerging biomarkers of higher cardiovascular risk in patients with diabetes and hypertension.

\section{Methods}

\section{Study design}

This randomized, double-blind, controlled study was conducted at the Department of Internal Medicine and Therapeutics, University of Pavia, PAVIA, Italy.
The study protocol was conducted in accordance with the Declaration of Helsinki and its amendments, and the Good Clinical Practice Guidelines. It was approved by the each Ethical Committee and all patients provided written informed consent prior to entering the study. Trial registration: ClinicalTrials.gov NCT02064218.

\section{Patients}

We enrolled 213 outpatients (Table 1 ), aged $\geq 18$ of either sex, satisfying all the following inclusion criteria:

- overweight (body mass index between 25.0 and $\left.29.9 \mathrm{~kg} / \mathrm{m}^{2}\right)$;

- mild to moderate hypertension defined by systolic blood pressure (SBP) $\geq 140 \mathrm{mmHg}<180 \mathrm{mmHg}$ and/or diastolic blood pressure (DBP) $\geq 90 \mathrm{mmHg}$ $<105 \mathrm{mmHg}$;

- normocholesterolemic [low density lipoprotein cholesterol (LDL-C) $<160 \mathrm{mg} / \mathrm{dl}]$;

- well controlled type 2 diabetes mellitus $\left(\mathrm{HbA}_{1 \mathrm{c}} \leq\right.$ 7.5\%); all classes of anti-diabetic medications were allowed;

- in primary prevention;

- naïve to anti-hypertensive and anti-platelet treatment in order to avoid possible interactions on primary objective of our study.

The exclusion criteria were secondary hypertension, severe hypertension (SBP $\geq 180 \mathrm{mmHg}$ or $\mathrm{DBP} \geq 105 \mathrm{mmHg}$ ), hypertrophic cardiomyopathies due to etiologies other than hypertension, history of heart failure, history of angina, stroke, transient ischemic cerebral attack, coronary artery bypass surgery or myocardial infarction any time prior to visit 1 , concurrent known symptomatic arrhythmia, liver dysfunction (AST or ALT values exceeding twofold the upper limit), creatinine $>1.5 \mathrm{mg} / \mathrm{dl}$, known hypersensitivity to the study drugs. Patients with previous gastric or duodenal bleedings and patients with previous intolerance to ASA were also

\section{Table 1 Baseline characteristics of enrolled patients}

\begin{tabular}{ll}
\hline Parameters & N \\
\hline $\mathrm{N}$ & 213 \\
Sex (M/F) & $106 / 107$ \\
Age (years) & $57.8 \pm 7.9$ \\
Smokers (M/F) & $23 / 18$ \\
$\mathrm{BMl}_{\left(\mathrm{kg} / \mathrm{m}^{2}\right)}$ & $27.7 \pm 1.8$ \\
$\mathrm{HbA}_{1 \mathrm{c}}(\%)$ & $6.7 \pm 0.7$ \\
\hline
\end{tabular}

Data are presented as mean \pm standard deviation.

$M$ males, $F$ females, $B M I$ body mass index, $H b A_{1 c}$ glycated hemoglobin. 
excluded. Pregnant women as well as women of childbearing potential were excluded.

For all the study duration, no other anti-inflammatory drugs (NSAIDs, immunosuppressive agents, antibiotics, etc.) other than ASA were allowed during the 6 months follow-up.

Suitable subjects, identified from review of case notes and/or computerized clinic registers were contacted personally or by telephone.

\section{Treatments}

The patients fulfilling the inclusion criteria, were randomized to amlodipine $5 \mathrm{mg} / \mathrm{day}$, or amlodipine $5 \mathrm{mg} /$ day + ASA $100 \mathrm{mg}$ for 3 months (Phase A); then, if adequate blood pressure control was reached $(\mathrm{BP}<140 / 90 \mathrm{mmHg}$ ), patients terminated the study; otherwise, they proceeded in Phase B of the trial, where amlodipine was up-titrated to $10 \mathrm{mg} /$ day for further 3 months and compared to amlodipine $10 \mathrm{mg}+$ ASA $100 \mathrm{mg}$ (Fig. 1).

All drugs were supplied as identical, opaque, white capsules in coded bottles to ensure the blind status of the study. Randomization was done using a drawing of envelopes containing randomization codes prepared by a statistician. A copy of the code was provided only to the responsible person performing the statistical analysis. The code was only broken after database lock, but could have been broken for individual subjects in cases of an emergency. Medication compliance was assessed by counting the number of pills returned at the time of specified clinic visits. At baseline, we weighed participants and gave them a bottle containing a supply of the study medication for at least 100 days. Throughout the study, we instructed patients to take their first dose of new medication on the day after they were given the study medication. At the same time, all unused medication was retrieved for inventory. All medications were provided free of charge.

\section{Diet and exercise}

All patients were already following a controlled-energy diet (near $600 \mathrm{kcal}$ daily deficit) based on American Heart Association (AHA) recommendations [11] that included $50 \%$ of calories from carbohydrates, $30 \%$ from fat ( $6 \%$ saturated), and $20 \%$ from proteins, with a maximum cholesterol content of $300 \mathrm{mg} /$ day and $35 \mathrm{~g} /$ day of fibre. Patients were not treated with vitamins or mineral preparations during the study.

For all the study duration, patients of both arms were encouraged to continue to follow an adequate lifestyle. Standard diet advice was given by a dietician and/or specialist doctor. Dietician and/or specialist doctor periodically provided instruction on dietary intake recording procedures as part of a behaviour modification program and then later used the subject's food diaries for counselling. Individuals were also encouraged to increase their physical activity by walking briskly for $20-30 \mathrm{~min}, 3-5$ times per week, or by cycling.

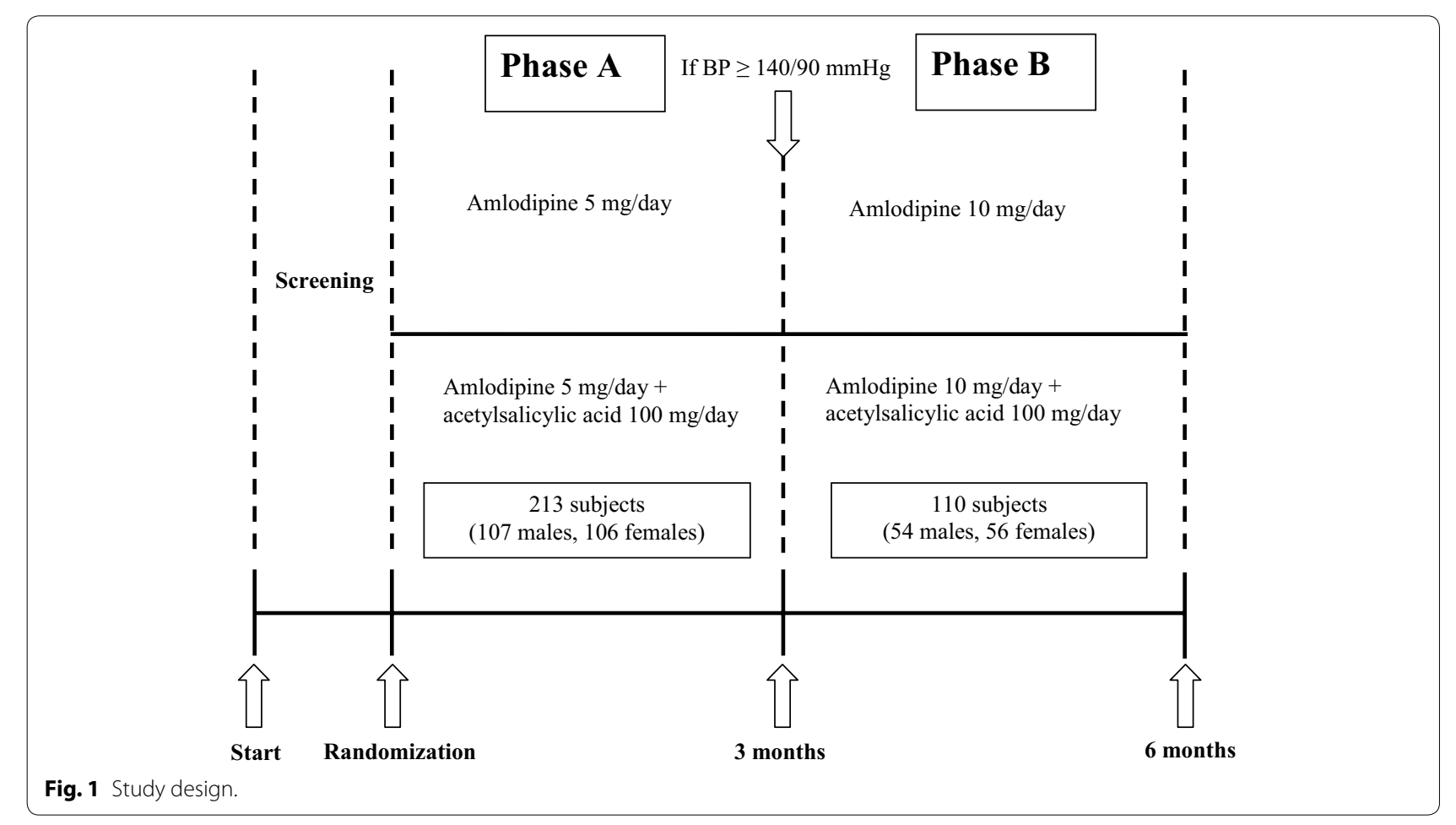




\section{Assessments}

Before starting the study, all patients underwent an initial screening assessment that included a medical history, physical examination, vital signs, and a 12-lead electrocardiogram. We assessed blood pressure (BP). We also collected blood sample to evaluate: high sensitivity $\mathrm{C}$-reactive protein (Hs-CRP), adiponectin (ADN), tumor necrosis factor- $\alpha$ (TNF- $\alpha$ ), interleukin-1 $\beta$ (IL$1 \beta), \mathrm{MPO}, \mathrm{sCDL40}$. All parameters were assessed at baseline, and after 3 months (at the end of Phase A) for all patients, and after further 3 months (at the end of Phase B only) only for patients proceeding in Phase B of the trial.

All plasmatic parameters were determined after a $12-\mathrm{h}$ overnight fast. Venous blood samples were taken for all patients between 08.00 and 09.00 A.M. We used plasma obtained by addition of $\mathrm{Na}_{2}$-EDTA, $1 \mathrm{mg} / \mathrm{ml}$, and centrifuged at 3,000 $\mathrm{g}$ for $15 \mathrm{~min}$ at $4^{\circ} \mathrm{C}$. Immediately after centrifugation, the plasma samples were frozen and stored at $-80^{\circ} \mathrm{C}$ for no more than 3 months. All measurements were performed in a central laboratory.

Blood pressure measurements were obtained from each patient (left arm) in the sitting position by physicians blinded to treatment using a standard mercury sphygmomanometer (Erkameter 3000; ERKA, Bad Tolz, Germany) (Korotkoff I and V) with a cuff of appropriate size. Blood pressure has been always measured in the morning before daily drug intake (i.e., at trough $22-24 \mathrm{~h}$ after dosing) and after the subject has rested $10 \mathrm{~min}$ in a quiet room. Three successive BP readings were obtained at 1-min intervals and averaged.

Heart rate was measured by pulse palpation for $30 \mathrm{~s}$, just before the BP measurements.

Body weight was measured with light clothes and without shoes and BMI was calculated as the weight in $\mathrm{kg}$ divided by height in $\mathrm{m}$ squared.

High sensitivity $C$-reactive protein was measured with use of latex-enhanced immunonephelometric assays on a BN II analyser (Dade Behring, Newark, Delaware, USA). The intra- and interassay coefficient of variations $(\mathrm{CsV})$ were 5.7 and $1.3 \%$, respectively [12].

Adiponectin level was determined using EnzymeLinked Immunosorbent Assay (ELISA) kits (B-bridge International, Sunnyvale, CA, USA). Intraassay CsV were $3.6 \%$ for low-control sample and 3.3\% for high-control sample, whereas interassay $\mathrm{CsV}$ were $3.2 \%$ for low-control sample and $7.3 \%$ for high-control samples, respectively [13].

Tumor necrosis factor- $\alpha$ level was assessed using commercially available ELISA kits according to manufacturer's instructions (Titer-Zyme EIA kit; Assay Designs, Ann Arbor, MI, USA). Intraassay CsV were 4.5\% for lowand $3.6 \%$ for high-concentration samples, whereas the interassay CsV were $6.0 \%$ for low and $11.8 \%$ for high-concentration samples, respectively [14].

We used a human cytokine 27-Bio-Plex assay kit (BioRad Laboratories, Milan, Italy), a bead-based multiplex immunoassay for IL-1 $\beta$. This technology has the capacity to measure several cytokines/cytokine receptors and growth factors simultaneously in small volumes of plasma with high accuracy and sensitivity [15]. The lower detection limit was $0.2-19.3 \mathrm{pg} / \mathrm{mL}$. The samples were read on a Bio-Plex 200 instrument equipped with the software bioplex manager, version 4.1, (Bio-Rad Laboratories, Hercules, CA, USA), using a five-parameter non-linear regression formula to compute sample concentrations from the standard curves.

Myeloperoxidase was assessed using commercially available ELISA kits according to manufacturer's instructions ( $R$ \& D Systems, Minneapolis, MN, USA). The intraand interassay $\mathrm{CsV}$ were 7.7 and $8.3 \%$, respectively [16].

Soluble CD40 ligand was assessed using commercially available ELISA kits according to manufacturer's instructions ( $\mathrm{R} \& \mathrm{D}$ Systems, Minneapolis, MN, USA). The intraand interassay $\mathrm{CsV}$ were 4.5 and $6.0 \%$, respectively [17].

\section{Statistical analysis}

Data are expressed as mean \pm standard deviation (SD). The statistical analysis of the data was performed by the statistical analysis software (SAS) system, version 6.12 (SAS Institute, Inc., Cary, NC, USA). The differences between the two groups in baseline characteristics were analyzed by the two-tailed Student's $t$ test. Intervention effects were adjusted for additional potential confounders (sex, smoking status, and age) using analysis of covariance (ANCOVA). Continuous variables were tested using a two-way repeated measures analysis of variance (ANOVA). Differences between baseline and 3-months of treatment in each group were analyzed with the Wilcoxon signed rank test [18]. Non-parametric tests were also employed in the statistical analysis of the data, because some data were not normally distributed (Kolmogorov-Smirnov test). The statistical significance of the independent effects of treatments on the other variables was determined using ANCOVA taking the baseline level of each parameter as a covariate.

Findings of $\mathrm{p}<0.05$ were considered significant. Considering as clinically significant a difference of at least $10 \%$ compared with the baseline and an alpha error of 0.05 , the actual sample size was adequate to obtain a power higher than 0.80 for all measured variables.

\section{Results}

\section{Study sample}

We enrolled 213 patients; 107 were randomized to amlodipine $5 \mathrm{mg}$, and 106 to amlodipine $5 \mathrm{mg}+$ ASA 
$100 \mathrm{mg} ; 110$ patients did not reach an adequate blood pressure control and continued in the second phase of the study with up-titration to amlodipine $10 \mathrm{mg}$ (54 subjects) or amlodipine $10 \mathrm{mg}+$ ASA $100 \mathrm{mg}$ (56 subjects). Five patients did not complete the first phase of the study (four patients in amlodipine $5 \mathrm{mg}$ group and one patient in amlodipine $5 \mathrm{mg}+$ ASA group) and three patients (two patients in amlodipine $10 \mathrm{mg}$ group and one patient in amlodipine $10 \mathrm{mg}+$ ASA group) did not complete the second phase of the trial. The reason for premature withdrawal were: lost to follow-up, peripheral edema, epigastralgy, withdrawal of informed consent. At baseline, no differences between the two groups were recorded. A list of anti-diabetic treatments taken at the beginning of the study was reported in Table 2 .

\section{Blood pressure}

We recorded a decrease of SBP ( $-6.5 \%$ with amlodipine $5 \mathrm{mg},-5.9 \%$ with amlodipine $5 \mathrm{mg}+\mathrm{ASA},-13.2 \%$ with amlodipine $10 \mathrm{mg},-13.5 \%$ with amlodipine $10 \mathrm{mg}+\mathrm{ASA}$ ). A similar trend was observed for DBP $(-8.2 \%$ with

\section{Table 2 Anti-diabetic drugs taken before randomisation}

\begin{tabular}{|c|c|}
\hline Parameters & $\mathbf{N}$ \\
\hline N & 213 \\
\hline $\mathrm{M} / \mathrm{F}$ & 106/107 \\
\hline Lifestyle & $5(2.34) 2 / 3)$ \\
\hline Sulfonylureas, n (\%) (M/F) & $42(19.7)(18 / 24)$ \\
\hline Glyburide & $3(7.1)(1 / 2)$ \\
\hline Glimepiride & $17(40.5)(10 / 7)$ \\
\hline Gliclazide & $22(52.4)(12 / 10)$ \\
\hline Biguanides, $n(\%)(M / F)$ & $153(71.8)(71 / 82)$ \\
\hline Metformin & $153(100)(71 / 82)$ \\
\hline Glinides, n (\%) (M/F) & $32(15.0)(17 / 15)$ \\
\hline Repaglinide & $32(100)(17 / 15)$ \\
\hline$\alpha$-glucosidase inhibitors, $n$ (\%) (M/F) & $33(15.5)(14 / 19)$ \\
\hline Acarbose & $33(100)(14 / 19)$ \\
\hline Thiazolidinediones, n (\%) (M/F) & $28(13.1)(15 / 13)$ \\
\hline Pioglitazone & $24(85.7)(12 / 12)$ \\
\hline Rosiglitazone & $4(14.3)(3 / 1)$ \\
\hline DPP-4 inhibitors, $n(\%)(M / F)$ & $33(15.5)(17 / 16)$ \\
\hline Sitagliptin & $12(36.4)(6 / 6)$ \\
\hline Vildagliptin & $10(30.3)(6 / 4)$ \\
\hline Saxagliptin & $7(21.2)(3 / 4)$ \\
\hline Linagliptin & $4(12.1)(2 / 2)$ \\
\hline GLP-1 analogs, n (\%) (M/F) & $15(7.0)(8 / 7)$ \\
\hline Exenatide & $10(66.7)(7 / 3)$ \\
\hline Liraglutide & $5(33.3)(2 / 3)$ \\
\hline
\end{tabular}

$M$ males, $F$ females, DPP-4 dipeptidyl peptidase-4, GLP-1 glucagon-like peptide-1. amlodipine $5 \mathrm{mg},-9.4 \%$ with amlodipine $5 \mathrm{mg}+\mathrm{ASA}$, $-14.8 \%$ with amlodipine $10 \mathrm{mg},-15.1 \%$ with amlodipine $10 \mathrm{mg}+$ ASA). No differences between amlodipine or amlodipine + ASA were recorded (Tables 3, 4).

\section{New markers of cardiovascular risk}

After 3 months of therapy, no variations of the above cited markers were recorded with amlodipine alone. Patients treated with amlodipine $5 \mathrm{mg}+$ ASA $100 \mathrm{mg}$, instead, showed a reduction of MPO, and sCDL40, compared to baseline ( -9.7 and $-15.7 \%$, respectively), and to amlodipine alone $(-5.1$ and $-13.6 \%)$. One hundred and seven patients continued the study, and were up-titrated to amlodipine $10 \mathrm{mg}+$ ASA $100 \mathrm{mg}$ or to amlodipine $10 \mathrm{mg}$ alone. We observed a decrease of MPO (-6.4\% for amlodipine alone, and $-15.0 \%$ for amlodipine + ASA), and sCDL40 ( $-5.1 \%$ for amlodipine alone, and $-24.1 \%$ for amlodipine + ASA) in both groups compared to baseline, even if values recorded with amlodipine $10 \mathrm{mg}+$ ASA were lower than the ones recorded with amlodipine $10 \mathrm{mg}$ alone ( -9.2 and $-20.0 \%$, respectively) (Tables 3, 4).

\section{Inflammatory markers}

We did not record any variations of inflammatory markers after 3 months of amlodipine monotherapy. In the group treated with amlodipine $5 \mathrm{mg}+$ ASA $100 \mathrm{mg}$, instead, there was a reduction of Hs-CRP $(-15.0 \%)$, and TNF- $\alpha(-21.7 \%)$, and an increase of ADN $(+15.0 \%)$ compared to baseline, and to amlodipine alone $(-10.5,-14.3$ and $+9.7 \%$, respectively). Regarding IL- $1 \beta$, it decreased with amlodipine $5 \mathrm{mg}+$ ASA $100 \mathrm{mg}$ compared to baseline $(-50.0 \%)$, but no differences were recorded compared to amlodipine alone. In patients continuing the study, we recorded a decrease of Hs-CRP $(-20.0 \%$ with amlodipine and $-35.0 \%$ with amlodipine +ASA), and TNF- $\alpha$ ( $-13.1 \%$ with amlodipine and $-26.1 \%$ with amlodipine + ASA), and an increase of ADN $(+11.7 \%$ with amlodipine and $+22.1 \%$ with amlodipine + ASA) compared to baseline. Values recorded with amlodipine $10 \mathrm{mg}+$ ASA were better than the ones recorded with amlodipine $10 \mathrm{mg}$ alone $(-18.8,-15$ and $+11.8 \%$, respectively). Regarding IL- $1 \beta$, it decreased compared to baseline only with amlodipine $10 \mathrm{mg}+$ ASA $(-50 \%)$ (Tables 3, 4).

\section{Adverse events}

No significant serious adverse events were reported. We recorded six episode of epistaxis, and four episodes of epigastralgy in patients taking ASA, and four episodes of peripheral edema in amlodipine $10 \mathrm{mg}$ groups; all events were reported as mild. 
Table 3 Data of patients completing Phase A of the trial

\begin{tabular}{|c|c|c|c|c|}
\hline \multirow[t]{2}{*}{ Parameters } & \multicolumn{2}{|c|}{ Amlodipine 5 mg } & \multicolumn{2}{|c|}{ Amlodipine $5 \mathrm{mg}+$ ASA $100 \mathrm{mg}$} \\
\hline & Baseline & 3 months & Baseline & 3 months \\
\hline N & 107 & 103 & 106 & 105 \\
\hline $\operatorname{Sex}(M / F)$ & $54 / 53$ & $51 / 52$ & $53 / 53$ & $53 / 52$ \\
\hline Smokers (M/F) & $12 / 10$ & $11 / 10$ & $12 / 9$ & $12 / 8$ \\
\hline $\mathrm{SBP}(\mathrm{mmHg})$ & $156.4 \pm 9.4$ & $145.2 \pm 8.4^{*}$ & $153.6 \pm 9.0$ & $146.1 \pm 8.8^{*}$ \\
\hline $\mathrm{DPB}(\mathrm{mmHg})$ & $95.9 \pm 5.5$ & $88.9 \pm 4.1^{*}$ & $97.2 \pm 5.9$ & $87.7 \pm 3.9^{*}$ \\
\hline $\mathrm{Hs}-\mathrm{CRP}(\mathrm{mg} / \mathrm{l})$ & $2.1 \pm 0.9$ & $1.9 \pm 0.7$ & $1.9 \pm 0.7$ & $1.7 \pm 0.5^{*} \wedge$ \\
\hline $\mathrm{ADN}(\mu \mathrm{g} / \mathrm{ml})$ & $5.4 \pm 1.2$ & $5.6 \pm 1.2$ & $5.2 \pm 1.0$ & $6.2 \pm 1.8^{*} \wedge$ \\
\hline TNF- $\alpha(p g / m l)$ & $2.4 \pm 0.9$ & $2.1 \pm 0.7$ & $2.3 \pm 0.8$ & $1.8 \pm 0.5^{*} \wedge$ \\
\hline $\mathrm{IL}-1 \beta(\mathrm{pg} / \mathrm{ml})$ & $0.6 \pm 0.5$ & $0.5 \pm 0.3$ & $0.6 \pm 0.5$ & $0.3 \pm 0.2^{*}$ \\
\hline MPO (ng/ml) & $780.1 \pm 220.3$ & $740.3 \pm 220.4$ & $776.5 \pm 218.5$ & $702.7 \pm 114.4^{*} \wedge$ \\
\hline sCDL40 (pg/ml) & $1254.4 \pm 110.2$ & $1231.3 \pm 102.1$ & $1260.7 \pm 119.5$ & $1064.5 \pm 92.9^{*} \wedge$ \\
\hline
\end{tabular}

Data are expressed as mean \pm standard deviation.

$M$ males, $F$ females, $H s$-CRP high sensitivity C-reactive protein, $A D N$ adiponectin, TNF- $\alpha$ tumor necrosis factor- $\alpha, I L-1 \beta$ interleukin- $1 \beta, M P O$ myeloperoxidase, $s C D L 40$ soluble CD40 ligand.

* $p<0.05$ vs baseline.

$\wedge p<0.05$ vs amlodipine.

Table 4 Data of patients entering the Phase B of the trial

\begin{tabular}{|c|c|c|c|c|}
\hline \multirow[t]{2}{*}{ Parameters } & \multicolumn{2}{|c|}{ Amlodipine $10 \mathrm{mg}$} & \multicolumn{2}{|c|}{ Amlodipine $10 \mathrm{mg}+\mathrm{ASA} 100 \mathrm{mg}$} \\
\hline & Baseline & 3 months & Baseline & 3 months \\
\hline N & 54 & 52 & 56 & 55 \\
\hline $\operatorname{Sex}(M / F)$ & $25 / 29$ & $24 / 28$ & $29 / 27$ & $28 / 27$ \\
\hline Smokers (M/F) & $4 / 3$ & $4 / 3$ & $5 / 3$ & $5 / 3$ \\
\hline $\mathrm{SBP}(\mathrm{mmHg})$ & $153.7 \pm 9.1$ & $134.8 \pm 6.1^{\circ}$ & $154.2 \pm 9.2$ & $134.2 \pm 5.9^{\circ}$ \\
\hline $\mathrm{DPB}(\mathrm{mmHg})$ & $95.1 \pm 5.2$ & $82.5 \pm 3.2^{\circ}$ & $96.8 \pm 5.7$ & $82.2 \pm 3.1^{\circ}$ \\
\hline Hs-CRP (mg/l) & $2.0 \pm 0.8$ & $1.6 \pm 0.5^{*}$ & $2.0 \pm 0.8$ & $1.3 \pm 0.4^{\circ} \wedge$ \\
\hline ADN $(\mu \mathrm{g} / \mathrm{ml})$ & $5.1 \pm 1.1$ & $6.0 \pm 1.5^{*}$ & $5.3 \pm 1.2$ & $6.8 \pm 1.9^{\circ} \wedge$ \\
\hline $\mathrm{TNF}-\alpha(\mathrm{pg} / \mathrm{ml})$ & $2.5 \pm 0.8$ & $2.0 \pm 0.6^{*}$ & $2.2 \pm 0.7$ & $1.7 \pm 0.4^{\circ} \wedge$ \\
\hline $\mathrm{IL}-1 \beta(\mathrm{pg} / \mathrm{ml})$ & $0.5 \pm 0.8$ & $0.5 \pm 0.3$ & $0.5 \pm 0.4$ & $0.3 \pm 0.2^{*}$ \\
\hline MPO (ng/ml) & $775.2 \pm 219.5$ & $728.1 \pm 217.3^{*}$ & $774.2 \pm 216.2$ & $661.2 \pm 112.3^{\circ} \wedge$ \\
\hline $\mathrm{sCDL40}(\mathrm{pg} / \mathrm{ml})$ & $1252.8 \pm 118.9$ & $1198.4 \pm 99.7^{*}$ & $1268.5 \pm 118.2$ & $958.3 \pm 82.4^{\circ} \wedge$ \\
\hline
\end{tabular}

Data are expressed as mean \pm standard deviation.

$M$ males, $F$ females, $H s$-CRP high sensitivity C-reactive protein, $A D N$ adiponectin, $T N F-\alpha$ tumor necrosis factor- $\alpha, I L-1 \beta$ interleukin- $1 \beta, M P O$ myeloperoxidase, sCDL40 soluble CD40 ligand.

${ }^{*} p<0.05$ vs baseline.

${ }^{\circ} \mathrm{p}<0.01$ vs baseline.

$\wedge p<0.05$ vs amlodipine.

\section{Discussion}

We observed that the addition of ASA to amlodipine therapy in patients with diabetes was effective, in primary prevention, in reducing some inflammatory and new emerging biomarkers in cardiovascular risk stratification, suggesting a favourable effects of ASA in this kind of patients. In particular, our data showed a reduction of Hs-CRP not reported by Vaucher et al. [19]. These
Authors reported that low-dose aspirin for cardiovascular prevention does not impact plasma pro-inflammatory cytokines and Hs-CRP levels, however, in their study, only a small portion of the studied population was affected by diabetes, while our population was all affected by diabetes.

In our study we also observed a reduction of MPO and sCDL40 in patients treated with ASA. Reduction of 
sCDL40 was reported also by Rosiak et al. that reported a significant reduction of $\mathrm{Hs}-\mathrm{CRP}, \mathrm{sCD} 40 \mathrm{~L}$, and interleukin-6 with ASA [20].

Differently from what reported in literature [21, 22] where, in patients with diabetes, age proved to be the most important predictive factor of laboratory response to ASA therapy, we did not record different effects of ASA according to different age; this is probably due to the fact that, in our population, age standard deviation was very low, suggesting a homogeneous data. The antiinflammatory action observed in our study can be only partially explained by blood pressure reduction, because amlodipine dose was identical in both arms. Moreover, we chose to use amlodipine as anti-hypertensive agent because, from the evidence published in literature, amlodipine proved to be neutral on Hs-CRP, both used alone [23], or in addition to atorvastatin [24], even if it increased adiponectin both in combination with atorvastatin [24] and olmesartan [25]. All data collected suggest a protective effect linked to ASA use in primary prevention in patients with diabetes.

Regarding the mechanism of action throughout ASA acts, it is largely known that ASA is the archetypal non steroidal anti-inflammatory drug found to inhibit the cyclooxygenase (COX II) pathway of arachidonic acid metabolism [26], being anti-inflammatory at $1 \mathrm{~g}$ dose [27], but cardioprotective at lower doses $(75-150 \mathrm{mg} /$ day) through the inhibition of platelet-derived thromboxane $(\mathrm{Tx}) \mathrm{A}_{2}[28,29]$. ASA also inhibits pathways inherent to innate immunity including the production of $\mathrm{TxA}_{2}$ [30], which is suggested to facilitate the polymorphonuclear leukocyte (PMN)-platelet interaction that leads to PMN transmigration into inflamed tissues [31]. Moreover, ASA triggers the synthesis of novel lipid metabolites that directly halt leukocyte trafficking and elicit proresolution effects [32]. In addition, there is evidence that ASA down-regulates pro-inflammatory signaling pathways including NF- $\kappa \mathrm{B}$ [33]. This suggests that ASA may be anti-inflammatory at levels used in cardio-protection. This was confirmed by Morris et al. [34] that showed that ASA dampens innate immuno-mediated responses in humans by triggering 15-epi-lipoxin A4 from endothelial COX2 expressed in response to local injury, which subsequently prevents leukocyte accumulation to sites of tissue injury in an NO-dependent manner.

Of course our study has some limitations: for example, we evaluated only some inflammatory parameters and some new markers of cardiovascular disease, focusing our attention on a few of them. Moreover, it would be interesting to verify if the reduction of these biomarkers will have an impact on the reduction of cardiovascular events, but, to assess this, longer studies are needed.

\section{Conclusions}

The addition of ASA to amlodipine gave a better improvement of inflammatory parameters compared to amlodipine alone, suggesting a role of ASA in reducing inflammation and endothelial damage independently from the blood pressure reduction. These data suggest that the use of ASA in primary prevention could be useful in patients with type 2 diabetes mellitus and hypertension.

\begin{abstract}
Authors' contributions
Prof. GD, Dr. AM and Dr. PM designed the study, researched data and wrote the manuscript; Dr. AD'A processed and analyzed collected samples; Dr. RMP researched data. All authors read and approved the final manuscript.
\end{abstract}

\section{Author details}

${ }^{1}$ Department of Internal Medicine and Therapeutics, University of Pavia, and Fondazione IRCCS Policlinico San Matteo, P.le C. Golgi, 2, 27100 Pavia, Italy. ${ }^{2}$ Center for the Study of Endocrine-Metabolic Pathophysiology and Clinical Research, University of Pavia, Pavia, Italy. ${ }^{3}$ Laboratory of Molecular Medicine, University of Pavia, Pavia, Italy. ${ }^{4}$ PhD School in Experimental Medicine, University of Pavia, Pavia, Italy.

\section{Compliance with ethical guidelines}

\section{Competing interests}

The authors declare that they have no competing interest.

\section{Funding}

The authors' research was supported by IRCCS Policlinico San Matteo Foundation with a grant for "Ricerca Corrente" project. The funding source of this study did not have any role in the study design, or in conducting the practical work of writing the report.

\section{Statement of Human Rights}

All procedures followed were in accordance with the ethical standards of the responsible committee on human experimentation and with the Helsinki Declaration of 1975, as revised in 2008. Informed consent was obtained from all patients for being included in the study. Trial registration: ClinicalTrials.gov NCT02064218

Received: 8 April 2015 Accepted: 2 July 2015

Published online: 30 July 2015

\section{References}

1. Whiting DR, Guariguata L, Weil C, Shaw J (2011) IDF diabetes atlas: global estimates of the prevalence of diabetes for 2011 and 2030. Diabetes Res Clin Pract 94:311-321

2. Stamler J, Vaccaro O, Neaton JD, Wentworth D (1993) Diabetes, other risk factors, and 12-year cardiovascular mortality for men screened in the Multiple Risk Factor Intervention Trial. Diabetes Care 16(2):434-444

3. Mulnier HE, Seaman HE, Raleigh VS, Soedamah-Muthu SS, Colhoun HM, Lawrenson RA et al (2006) Risk of stroke in people with type 2 diabetes in the UK: a study using the general practice research database. Diabetologia 49(12):2859-2865

4. Vaccaro O, Franzini L, Miccoli R, Cavalot F, Ardigò D, Boemi M et al (2013) MIND.IT Study Group. Feasibility and effectiveness in clinical practice of a multifactorial intervention for the reduction of cardiovascular risk in patients with type 2 diabetes: the 2-year interim analysis of the MIND.IT study: a cluster randomized trial. Diabetes Care 36(9):2566-2572

5. http://www.aemmedi.it/news/single/1/standard_italiani_per_la_cura_ del_diabete_mellito_2014/.Accessed Jan 2015

6. American Diabetes Association (2015) Standards of medical care in diabetes-2015. Diabetes Care 38(Suppl 1):S1-S94 
7. Sirois C, Couture J, Grégoire JP (2012) Acetylsalicylic acid for primary prevention of cardiovascular diseases in older patients with diabetes: do the benefits overcome the risks? Ther Adv Drug Saf 3(5):213-226

8. Ogawa H, Nakayama M, Morimoto T, Uemura S, Kanauchi M, Doi N et al (2008) Low-dose aspirin for primary prevention of atherosclerotic events in patients with type 2 diabetes: a randomized controlled trial. JAMA 300:2134-2141

9. Belch J, MacCuish A, Campbell I, Cobbe S, Taylor R, Prescott R et al (2008) The prevention of progression of arterial disease and diabetes (POPADAD) trial: factorial randomised placebo controlled trial of aspirin and antioxidants in patients with diabetes and asymptomatic peripheral arterial disease. BMJ 337:a1840

10. Derosa G, D'Angelo A, Mugellini A, Pesce RM, Fogari E, Maffioli P (2012) Evaluation of emerging biomarkers in cardiovascular risk stratification of hypertensive patients: a 2-year study. Curr Med Res Opin 28(9):1435-1445

11. Rydén L, Standl E, Bartnik M, VandenBerghe G, Betteridge J, deBoer MJ et al (2007) Guidelines on diabetes, pre-diabetes, and cardiovascular diseases: executive summary. The task force on diabetes and cardiovascular diseases of the European Society of Cardiology (ESC) and of the European Association for the Study of Diabetes (EASD). Eur Heart J 28(1):88-136

12. Rifai N, Tracy RP, Ridker PM (1999) Clinical efficacy of an automated highsensitivity C-reactive protein assay. Clin Chem 45(12):2136-2141

13. Yamauchi T, Kamon J, Waki H, Terauchi Y, Kubota N, Hara Ket al (2001) The fat-derived hormone adiponectin reverses insulin resistance associated with both lipoatrophy and obesity. Nat Med 7(8):941-946

14. Zhang M, Tracey K (1988) The cytokine handbook, 3rd edn. Academic Press, San Diego

15. Khan SS, Smith MS, Reda D, Suffredini AF, McCoy JP Jr (2004) Multiplex bead array assays for detection of soluble cytokines: comparisons of sensitivity and quantitative values among kits from multiple manufacturers. Cytometry B Clin Cytom 61:35-39

16. Morishita K, Kubota N, Asano S, Kaziro Y, Nagata S (1987) Molecular cloning and characterization of cDNA for human myeloperoxidase. J Biol Chem 262(8):3844-3851

17. Graf D, Korthäuer U, Mages HW, Senger G, Kroczek RA (1992) Cloning of TRAP, a ligand for CD40 on human T cells. Eur J Immunol 22(12):3191-3194

18. Winer BJ (1971) Statistical principles in experimental design, 2nd edn. McGraw-Hill, New York

19. Vaucher J, Marques-Vidal P, Waeber G, Vollenweider P (2014) Cytokines and hs-CRP levels in individuals treated with low-dose aspirin for cardiovascular prevention: a population-based study (CoLaus study). Cytokine 66(2):95-100

20. Rosiak M, Postula M, Kaplon-Cieslicka A, Kondracka A, Trzepla E, Czlonkowski A et al (2013) Effect of ASA dose doubling versus switching to clopidogrel on plasma inflammatory markers concentration in patients with type 2 diabetes and high platelet reactivity: the AVOCADO study. Cardiol J. 20(5):545-551
21. Takahashi Y, Nishida Y, Nakayama T, Asai S (2013) Comparative effect of clopidogrel and aspirin versus aspirin alone on laboratory parameters: a retrospective, observational, cohort study. Cardiovasc Diabetol 12:87

22. Kaplon-Cieslicka A, Postula M, Rosiak M, Peller M, Kondracka A, Serafin A et al (2014) Younger age, higher body mass index and lower adiponectin concentration predict higher serum thromboxane B2 level in aspirintreated patients with type 2 diabetes: an observational study. Cardiovasc Diabetol 13:112

23. Irons BK, Trujillo A, Seifert CF, Simoni JS, Doctolero S, Abo-Salem E et al (2013) Effects of direct renin inhibition on atherosclerotic biomarkers in patients with stable coronary artery disease and type 2 diabetes mellitus. J Cardiovasc Pharmacol Ther 18(5):427-432

24. Tanaka M, Nishimura R, Nishimura T, Kawai T, Meguro S, Irie J et al (2014) Effect of single tablet of fixed-dose amlodipine and atorvastatin on blood pressure/lipid control, oxidative stress, and medication adherence in type 2 diabetic patients. Diabetol Metab Syndr 6:56

25. Khan BV, Merchant N, Rahman ST, Ahmad M, Parrott JM, Umar K et al (2013) Changes in central aortic pressure, endothelial function and biomarkers in hypertensive african-americans with the cardiometabolic syndrome: comparison of amlodipine/olmesartan versus hydrochlorothiazide/losartan. Cardiorenal Med 3:221-231

26. Vane JR (1971) Inhibition of prostaglandin synthesis as a mechanism of action for aspirin-like drugs. Nat New Biol 231(25):232-235

27. Flower RJ (1974) Drugs which inhibit prostaglandin biosynthesis. Pharmacol Rev 26(1):33-67

28. Reilly IA, FitzGerald GA (1987) Inhibition of thromboxane formation in vivo and ex vivo: implications for therapy with platelet inhibitory drugs. Blood 69(1):180-186

29. Hennekens CH, Sechenova O, Hollar D, Serebruany VL (2006) Dose of aspirin in the treatment and prevention of cardiovascular disease: current and future directions. J Cardiovasc Pharmacol Ther 11(3):170-176

30. Patrono C, Ciabattoni G, Pinca E, Pugliese F, Castrucci G, De Salvo A et al (1980) Low dose aspirin and inhibition of thromboxane B2 production in healthy subjects. Thromb Res 17(3-4):317-327

31. Weissmüller T, Campbell EL, Rosenberger P, Scully M, Beck PL, Furuta GT et al (2008) PMNs facilitate translocation of platelets across human and mouse epithelium and together alter fluid homeostasis via epithelial cellexpressed ecto-NTPDases. J Clin Invest 118(11):3682-3692

32. Clària J, Serhan CN (1995) Aspirin triggers previously undescribed bioactive eicosanoids by human endothelial cell-leukocyte interactions. Proc Natl Acad Sci USA 92(21):9475-9479

33. Grilli M, Pizzi M, Memo M, Spano P (1996) Neuroprotection by aspirin and sodium salicylate through blockade of NF-kappaB activation. Science 274(5291):1383-1385

34. Morris T, Stables M, Hobbs A, de Souza P, Colville-Nash P, Warner T et al (2009) Effects of low-dose aspirin on acute inflammatory responses in humans. J Immunol 183(3):2089-2096

\section{Submit your next manuscript to BioMed Central and take full advantage of:}

- Convenient online submission

- Thorough peer review

- No space constraints or color figure charges

- Immediate publication on acceptance

- Inclusion in PubMed, CAS, Scopus and Google Scholar

- Research which is freely available for redistribution

Submit your manuscript at 